\title{
Building information modeling concept in bridge construction
}

\author{
Ekaterina Shestakova ${ }^{1 *}$, Natalia Malshchukova ${ }^{1}$, and Sergey Chizhov ${ }^{1}$ \\ ${ }^{1}$ Emperor Alexander I St.Petersburg State Transport University, 9 Moskovsky pr., Saint Petersburg, \\ 190031, Russia
}

\begin{abstract}
This article is devoted to the initial stages of formation and the prospects of development of BIM technologies, the analysis of the general trends, process of formation of uniform resource space and training of professional engineering staff for transport infrastructure. The main objective of this article is the designation, the analysis of problems and formation of a comprehensive approaches within preparation of the modern level of development of design decisions for informational model which is capable to process in a complex an engineering, technological and economic component and will be relevant throughout all life cycle of an object. In articles authors presented results of poll to PGUPS on a subject "to BIM technology: training of specialists in the field of transport constructions" which convincingly show need of preparation and development of engineering potential for BIM introduction. In conclusions the concept of BIM for bridge projection taking into account start of pilot standard projects with use $3 \mathrm{D}$ - projections and with engaging of the modern methods of engineering is presented. The article also discusses the prospects for the development of design in Russia.
\end{abstract}

\section{The concept of BIM design}

The digital information model of an object consists of models that correspond to the life cycle of the object: engineering-geological, design, construction, subsequent service life operations. Executive operational models and other models, including all technological and economic information. The management phases in a bridge life cycle have become increasingly dependent upon information management. One of the main concepts of BIM technologies is a parametric approach to design, the idea of which is reduced to objectoriented modeling, i.e. object modeling is performed by using individual elements collected in data libraries that can be created independently, ordered from specialists, or obtained from manufacturers. Each approach has its pros and cons, but it is important to remember that the quality of a BIM model is determined by the quality of execution of its weakest element.

\footnotetext{
*Corresponding author: ekaterinamost6@gmail.com
} 


\section{Types of elements}

The transition to BIM technology is a complex process that requires time and resources. If basic problems such as buying SOFTWARE, creating new professions and training, defining BIM tasks in a project, etc., can be solved / improved gradually, from project to project, then filling in the "resource space" itself, creating library data, is a cumulative process that requires hard work, time and experience. If we consider the example of CIM, there are the following types of elements: basic, dependent, and independent elements auxiliary and annotative.

\section{Details of the elements}

According to the parametric approach, the simulated element has attribute data: geometric and non-geometric (attributes) parameters. As the project progresses, the parameters can be detailed or changed.

The level of detail of the element (LOD) is determined based on: the goals and required results of modeling, from BIM tasks, from the stages of project implementation, from the required data for the preparation of technical documentation. In other words, the LOD is determined based on the amount of minimal, reliable information that is needed for each project participant to complete their project tasks.

The main problem with defining detail levels is that when modeling, elements have different speeds and different amounts of detail. Therefore, there is a lack of information from contractors on the links between the model elements for full coordination. This occurs when the LOD400 does not yet exist before the " $\mathrm{C}$ " stage, and the LOD300 does not provide this information. This issue is widely discussed in the global BIM society, however, at the moment, there is no generally accepted European standard, and each country regulates it in its own way. According to SP 333.1325800.2017, 5 levels of detail are regulated in Russia, where intermediate levels are allowed but not defined. It is planned to link LOD400 with the classifier of construction resources OF the CA. Also, there are other breakdowns into levels of detail: LOD500 (Executive documentation), LOD600 (operation) and LOD700 (dismantling project).

\section{Classification of elements}

For full interaction of process participants, a unified classification system is used, which allows you to structure all information and provide a simplified search for the necessary data, as well as accurately identify the composition of the model at each stage of the object's life cycle.

A standardized classification system is the basis for creating a high-quality BIM model, since it determines the detail of the project: the more detailed the classifier is, the more detailed the model is.

Classifiers are designed to solve certain problems of the construction area in which they are developed. USACE BIM Minimum Modeling Matrix (M3) has created a clear tool in the form of a spreadsheet that allows you to interact within the project based on standard classifiers: OmniClass, UniFormat, MasterFormat or others.

Such classifier systems consist of a set of interconnected tables with basic information about the object model: from the engineering and geological conditions of the project to information about the project and the roles of all participants in the process. Each engineering field has its own characteristics, and therefore, it is difficult to create a single classification system that is convenient for everyone. 
BIM model design, construction and operation of buildings by Order of the President of the Russian Federation of 19 July 2018, the Prime Minister, says that in order to ensure the modernization of the construction area and the improvement of the construction quality: ... use of standard models for control systems (design, construction, operation, recycling), the formation of a library of standard project documentation for information modeling in construction has to be taken.

Currently, the Ministry of construction of the Russian Federation is updating the legal framework to restore the work on maintaining the register of standard project documentation. Thanks to standard design, you can achieve cost savings without losing quality, and the main problem of its kind - the lack of reference to engineering and geological conditions, can be solved using BIM modeling tools. This solution is being actively implemented in the field of PGS for state institutions, but it has not yet come to bridge construction. In domestic bridge construction, the "era of individual design", standard projects, unification and typification is observed only in the framework of large projects, such as the KAD, SPAD and ZSD.

When creating construction products, the system of relationships between construction participants is of great importance. Relationships between participants (investor, customer, general contractor, project manager, etc.) of construction projects and coordination of actions of participants in the production and technical process should be fixed in the organization's BIM standard. Rules for organizing work by production and technical departments (PTO) are reflected in SP 301.1325800.2017. The use of BIM technologies (information modeling — a modern approach to the generation process and to the management of data about a building throughout its life cycle) provides the Customer/Investor with the following advantages:

Reduced design time;

Reducing the number of alterations and errors in design and construction;

Accurate financial forecasting of the project implementation process;

Optimization of construction costs;

Improving the quality of operation and reducing operating costs due to detailed information about the object accumulated over the entire period of design and construction of the object.

In modern conditions, the successful implementation of an innovative project requires extensive use of information technologies. BIM is included in almost all construction cases and is considered a competitive advantage. The experience of the state transition to BIM in foreign countries shows that a key role is assigned to the technical customer and unified innovative software tools. At the moment, Russia has already started to develop its own domestic integrated solutions for information modeling technologies, adapted to Russian realities and taking into account the specifics of the organization. The existing domestic developments of Adept company allow closing all sections of construction projects after applying the $3 \mathrm{D}$ model: the schedule of work $4 \mathrm{D}$, the volume statement, the estimate $5 \mathrm{D}$, the executive documentation on the construction site 6D.

For the effectiveness of BIM technologies, it is necessary to launch pilot typical projects using 3D design, as well as take into account technical and economic indicators of typical models throughout the life cycle, automated assessment of the technical condition of bridge structures with analysis of the reasons that reduce the service life of the structure and methods of risk forecasting (using probability theory and modern methods of artificial intelligence online).

The transition to information modeling should be carried out using the integration of the national BIM platform and the automated information system OF the fgis $\mathrm{CA}$. In the coming years, it is necessary to create a single state industry digital platform that could provide the formation of libraries of BIM models, their accumulation and storage, as well 
as processing and analysis with the function of operational data exchange (technical and economic indicators) about the objects of artificial structures throughout the life cycle, as well as support for business processes, government functions and services within the life cycle management of objects using information modeling technology.

Consideration of the actual technical condition is necessary to provide reasonable suggestions for eliminating the identified shortcomings and recommendations for improving the efficiency of safety management of the state of objects and to formulate a strategy aimed at improving the efficiency of spending funds on repairs.

In addition, it is necessary to classify, type and unify objects by the main stages of the life cycle (design, construction, repair and reconstruction), as well as differentiate them depending on the operational, natural and climatic conditions of operation and types of structures of artificial structures for both railway and road bridges. At the same time, the main goal is to optimize the decision-making time, approval levels, timing and volume of restoration work with the required level of reliability that ensures the safety of traffic at set speeds. This requires online status monitoring based on innovative software and a network of sensors. Sensor technology in different countries has become an attractive tool to facilitate remote and continues health monitoring of large-scale bridges [1,2,3], the widest concrete concrete bridge [4,6], high-speed railway [5,7]. The smart Bridge Project Central Ring Road of the Moscow also includes Intelligent Sensor Networks. The recommended number of sensors with the required range for measuring the resulting deformations during operation has been determined (tensometer, inclinometer, accelerometer). The proposed monitoring system can provide an effective tool for structural monitoring and condition assessment of orthotropic steel bridges.

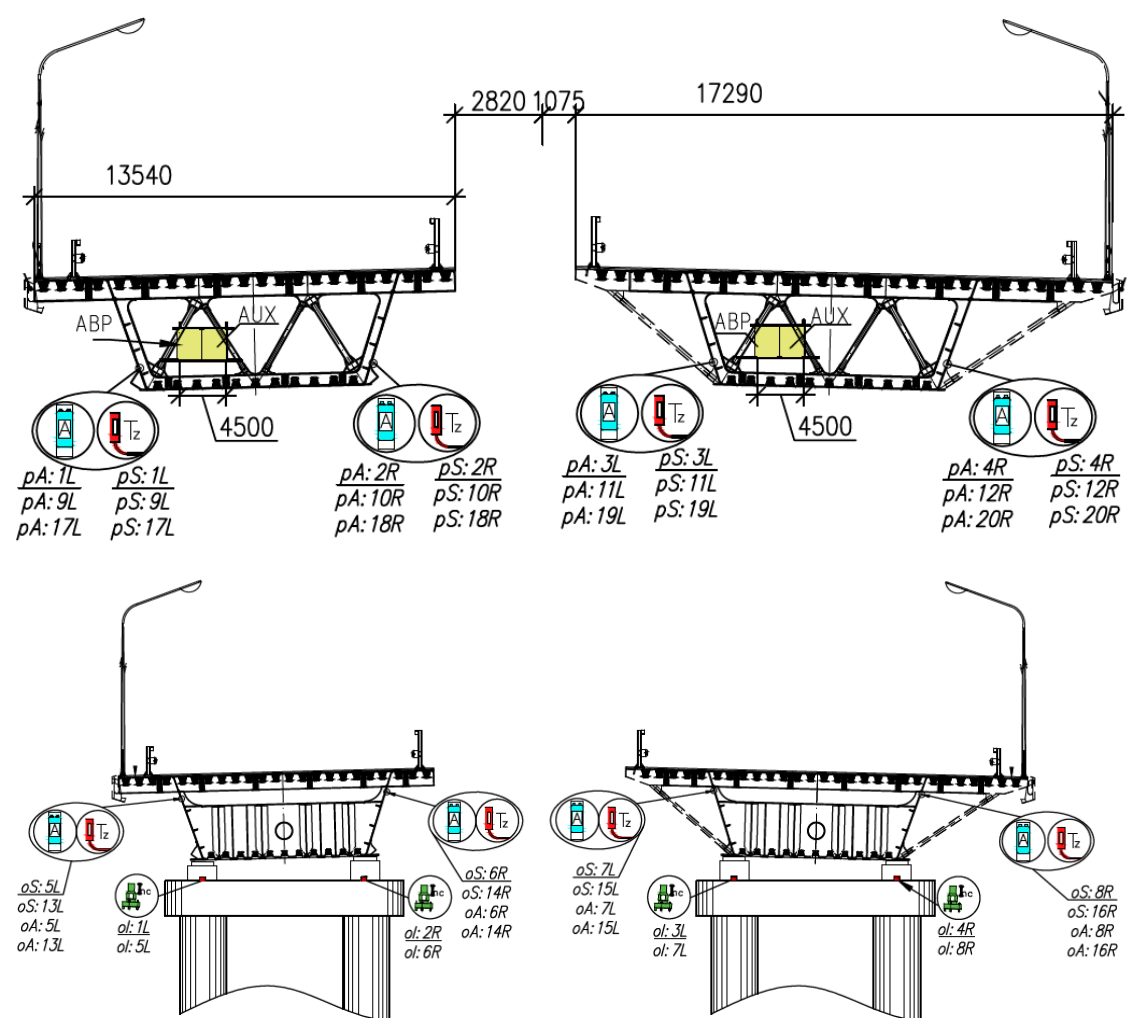

Fig. 1. Sensors and systems in structural health monitoring for highway bridges on an orthotropic steel deck in Central Ring Road of the Moscow 
One of the major problems arises when it is necessary to estimate the cost of capital repairs and reconstruction, since the cost of reconstruction depends significantly on the selected technological and design solutions, which, in turn, are identified at the stage of variant design. All estimates of the cost of construction and operation of structures must be considered during the entire life cycle in real time according to the criterion of minimizing the cost (price) and maximum service life while ensuring safe operation, taking into account a large number of parameters: with an assessment of the dynamics of prices and real prices in a constantly changing economic situation, road load, taking into account continuous monitoring under changing operating modes and established categories.

In order to optimize financial costs, the main recommendations in the field of construction operation are:

- in priority investments in the maintenance of structures, in order to reduce the cost of major repairs and reconstruction in the following years and increase the service life;

- to increase the durability of bridges through the use of innovative materials;

- in monitoring the financing of maintenance costs, taking into account technical and operational indicators and analyzing the reasons for deviation of actual results from the basic ones;

- optimal digital planning and regulation of transport infrastructure facilities on the basis of simulation.

\section{Training of engineering staff with the new BIM way of thinking}

Despite the scale and high potential of the digital innovation era, human potential is still the main component and driving force of progress. It should be noted that an important part of the global roadmaps for the introduction of new technology is the involvement of universities and colleges in the regular activity of BIM, holding workshops and seminars on their basis.

The survey conducted among companies in the construction industry of St. Petersburg, students and teachers of psups showed the following results (fig.2,3): training of specialists in the use of information modeling technologies "BIM-TECHNOLOGIES" should be started at the Institute and constantly improved.

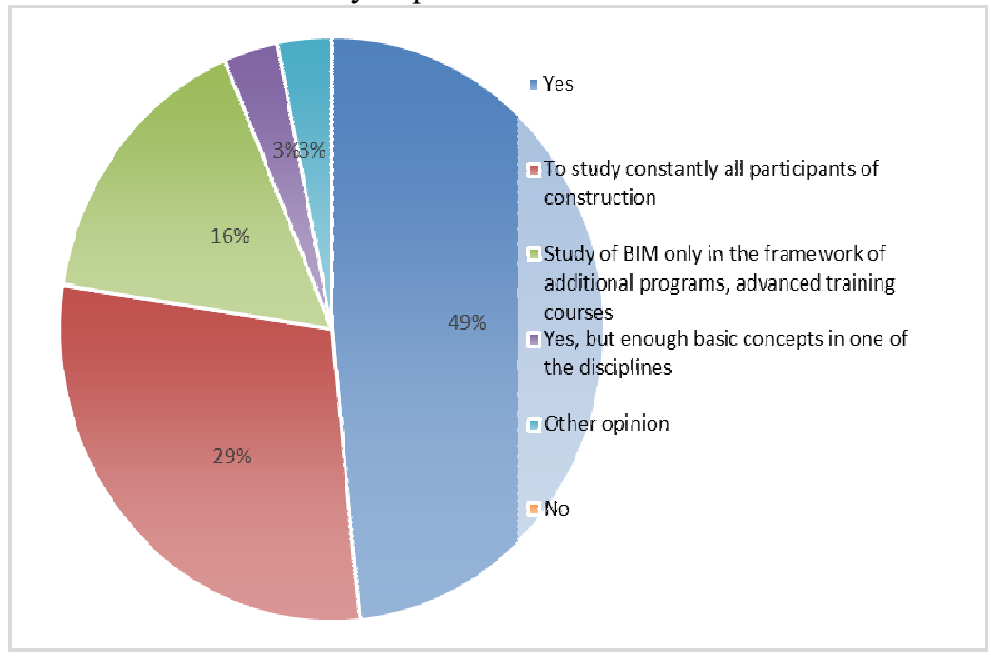

Fig. 2. Chart of respondents 'responses to the question:" do we Need appropriate programs in universities to "grow" a new generation of BIM specialists?»

More than half $(57 \%)$ of the users of the social network who followed the link after 
reading the publication about the survey answered the questions.

It is reasonable to expect that this percentage shows the degree of implementation and relevance of BIM solutions in St. Petersburg. The survey among users of the social network was conducted on 27.02-01.03.2019. It was attended by 54 respondents from 18 to 83 years old using a mobile phone $88 \%$ (12\% from a computer). The survey results shown in the charts, were obtained as a result of answers to 2 questions on BIM. One of the questions was: "in your opinion, BIM is a technology with a scope...".

The answer to this question, which received a maximum percentage of $68 \%$, confirmed the universal role and corresponds as much as possible to the current definition of new technology in the latest standards and set of rules - "for all capital buildings and structures throughout the life cycle".

The percentage of those who want to get an education based on new technologies: ranges from $16-49 \%$, depending on the programs and forms of education. "The future belongs to those who are constantly learning" - this is the motto of a third of respondents $(29 \%)$. Real success comes only to those who are constantly searching for knowledge and improving professional competencies." The genius of our twentieth century is expressed in engineering, " said Albert Einstein. But, genius is $99 \%$ of hard work and only $1 \%$ of talent and luck.

The authors of the article hope that the consolidation of the professional community forces with the participation of universities at the TC 465 site will create a single center of competence necessary for training specialists for effective work on the implementation of BIM technologies in digital construction. The corresponding order was published on the Rosstandart website in the summer of 2019.

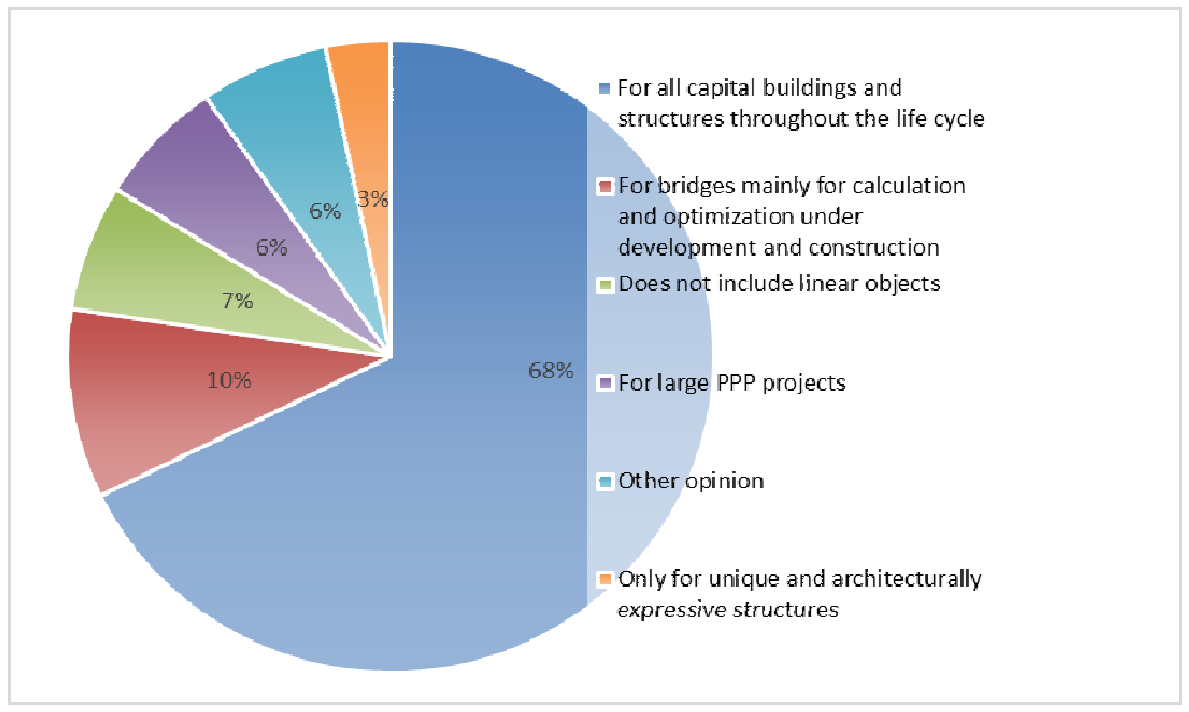

Fig.3 Chart of respondents responses to the question: «in your opinion, BIM is a technology with a scope of application...»

\section{Prospects for the Development of Design in Russia}

An important element in optimizing the planning of maintenance and repair costs is monitoring, monitoring and forecasting changes in the technical condition of equipment over the entire service life. This requires the adaptation of Big Data solutions when building data centers in the operating service for the purpose of integration, synchronization and analysis of technical information. To improve the objectivity of the forecast requires that 
monitoring and diagnostics are carried out digitally with the intelligent processing and artificial intelligence multivariable characteristics, performance indicators, and their changes based on accurate calculations of residual life, prediction, efficiency of capital investments and prioritization of deadlines and risks [8].

Computer technologies have already crossed the threshold of 6D-modeling today, customers are interested in services such as 7D (Smart city) and 360 BIM. Among the main innovative technologies offered to use in advanced countries of the world in the implementation of unique transport infrastructure projects, within the framework of the "smart " concept cities " based on advanced information technologies, include: comprehensive Internet, 5G communication, "industry 4.0", "Internet of things (IoT), automation, and big data technology Data), new concepts of digital technologies and such as " Mobility as service "(MaaS), application of artificial intelligence, " smart» Trimble construction helmet, green innovation or eco-innovation, energy-saving technologies, energy-efficient lighting, etc [9, 10].

Building Information Modeling (BIM) has been widely adopted in the building industry, and its established methods and technologies show enormous potential in benefiting the transportation infrastructure has been increasing, although the research has mainly been focusing on roads, highways, and bridges. [11].

There is no "perfect" software product suitable for designing absolutely any bridge structures. Each product has its own advantages and disadvantages, and the choice of software is often dictated by the specifics of the tasks to be solved. Software systems under the General name "Bridge Management System" are widely used in the world. The main tasks of the Bridge Management System are: optimizing the cost of the bridge's life cycle and forecasting its service life; determining the need for maintenance, repair, reconstruction or replacement of the bridge in the future; choosing the most effective and economical operation strategy; extending the service life of transport structures; increasing the efficiency of the service life. Despite the fact that each of the European countries is developing its own bridge management system, in recent years, the influence of the American approach in determining the main principles has been noticeable. The Pontis system (from lat. and FR. means-bridge, the license is owned by AASHTO site http://aashtowarebridge.com/), an improved extended version 5.3 of AASHTO Ware Bridge Management (BrM) (formerly called Pontis), which has been in operation since 1993 and is used in 45 US States and several European countries. In November 2012, Bentley Systems announced the signing of a Memorandum of cooperation with the AASHTO Association and a year later introduced the InspectTech Collector Mobile app for the iPad. This is Bentley's new application for creating a wide range of mobile applications that will increase information mobility by ensuring data integrity at all stages of the infrastructure lifecycle. An example of using a mobile tablet computer in the AASHTO WareBrM (Pontis) software package, which includes an additional "3D interactive inspection" function since 2013, is presented. The world of the future is not a tablet, but holograms and 3D projections. An innovative concept, "Bridge Information Modeling" (acronym "BrIM"), was first introduced in 2005 by co-authors Shirole' and Chen [12].

According to the draft order " on approval Of the methodology for determining the estimated cost of work on the preparation of project documentation for non-production facilities using information modeling technology (BIM)", the estimated cost of preparing project and working documentation for construction, reconstruction and major repairs using BIM technologies will be calculated according to the developed methodology using base prices.

The project provides that the information model of the object should be performed in the IFC format according to SP 333.1325800.2017 " Information modeling in construction. Rules for creating an information model of objects at different stages of the life cycle." 
To design using BIM technologies, you must have a library of elements that the customer must provide. If it is not available, you can use the designer's library, which contains virtual copies of building elements with detailed characteristics.

The correction factor provides for designing using BIM technologies at certain levels of development of elements (LOD) of the model:

- PD with the level of study of LOD 300 elements (Appearance / appearance, construction, material, slopes, marking, fire resistance);

- $\quad$ RD with the level of elaboration of LOD 400 elements (Manufacturer, name and article in the catalog).

Also, the draft order takes into account the performance of additional work in the design process as part of the PD and RD:

- development of an engineering digital terrain model;

- development of a model of existing external engineering networks based on the initial data provided by the customer;

- development of a model of external on-site engineering networks of the object based on project documentation developed without the use of BIM;

- development of a model of planning organization of the territory of the construction site (master plan, vertical layout, landscaping);

- development of a model of architectural appearance and planning solutions;

- development of a model of the main load-bearing structures of the building;

- development of a model of the main highways of internal engineering systems of the building and the main engineering equipment;

- development of the model under the section " Technological solutions";

- development of a design model of building structures;

- development and refinement of the model of PIC elements (cranes, pits, fences, storage areas, temporary roads);

- development of a summary model in real coordinates;

- formation of a consolidated statement of work volumes from the BIM model;

- development of an architectural model;

- development of a model of building structures (with the exception of three-dimensional 3D) reinforcement in the section "reinforced concrete Structures" and complex 3D nodes based on attribute characteristics and flat (2D elements);

- development of a model of internal engineering systems (without modeling small cross-section cable products);

- $\quad$ creating a statement of work volumes from the BIM model.

\section{Conclusions}

The transition to information modeling should be carried out using a single national BIM technology platform and an automated information system of THE fgis CA, while for the effective use of this technology by all participants in the transport industry, it is necessary:

1. Formation of fully accessible libraries of BIM models of standard design documentation of bridge elements of structures with a classifier and common (agreed) libraries of elements with a common knowledge resource for integrated interaction of the parties involved at all stages of the object's life cycle;

2. Development of pilot model projects is carried out using 3D design, taking into account the technical and economic indicators of standard models throughout the life cycle, with the possibility of automated assessment of the technical condition of bridge structures, with an analysis of the reasons that reduce the service life of the structure and methods of risk forecasting (using probability theory and modern methods of artificial intelligence 
online);

3. In order to optimize the financial costs of the entire life cycle, consider competitive options and strategies, taking into account preferential investments in the maintenance of structures, in order to reduce the cost of major repairs and reconstruction in subsequent years and increase the service life;

4. Provide the latest approaches to the system of training engineering personnel in higher education institutions by introducing a basic course of training in BIM technology.

The main system of indicators, including a positive economic effect, will be achieved through the use of advanced technologies of a proactive approach using continuous data collection from sensors and their analysis, as shown in the preliminary study for bridge structures:

- return on investment in innovation-5-10\%; achievement of an annual long-term socioeconomic effect-5-10\%;

- reduction of the specific cost of the life cycle by increasing the inter-repair period and reducing costs and maintenance costs-30\%;

- reducing the growth of critical irreversible processes, which increases the probability of failure-free operation in relation to downtime, failures and gives a reduction in accident rate- $60 \%$.

\section{References}

1. S.S. Chen, A.M. Shirolé, Transportation Research Record, 3-12 (1976). DOI: 10.3141/1976-03

2. J.M. Ko, Y.Q. Ni, Engineering Structures, 27 (12 SPEC. ISS.), 1715-1725(2005). DOI: 10.1007/s11227-019-03045-8

3. X.-W. Ye, Y.-H. Su, P.-S. Xi, Sensors (Switzerland), 18 (2), (2018) DOI: $10.3390 / \mathrm{s} 18020491$

4. G. Zhou, A. Li, J. Li, M. Duan, Applied Sciences (Switzerland), 8 (1), (2018). DOI: 10.3390/app8010115

5. J. Gu et al., Journal of Railway Engineering Society, 36 (4), $54-59$ (2019). DOI: 10.1007/s11227-019-03045-8

6. H. Zhao, Y. Ding et al., Structural Health Monitoring, (2019) DOI: $10.1177 / 1475921719875630$

7. Y. Zhuo, X. Wang, J. Zhang, Journal of Railway Engineering Society, 32 (4), 10-15 (2015). DOI: 10.1007/s11227-019-03045-8

8. Z. Liang, L.P. Feng, N. Li, Bridge Maintenance, Safety, Management and Life Extension - Proceedings of the 7th International Conference of Bridge Maintenance, Safety and Management, IABMAS 2014, 1279-1283 (2014). DOI: 10.1007/s11227019-03045-8

9. M.O. Kebaili, K. Foughali et al., Procedia Computer Science, 58, 578-583 (2016). DOI: 10.1016/j.procs.2016.09.090

10. L.Y. Sui, Z.H. Chen et al., Applied Mechanics and Materials, 556-562, 5994-5998 (2014). DOI: 10.4028/www.scientific.net/AMM.556-562.5994

11. A. Costin, A. Adibfar et al., Automation in Construction, 94, 257-281 (2018). DOI: 10.1016/j.autcon.2018.07.001

12. A.M. Shirole, S.S. Chen et al., Bridge Maintenance, Safety, Management and LifeCycle Optimization - Proceedings of the 5th International Conference on Bridge Maintenance, Safety and Management, 1117-1124 (2010). 